\title{
НЕЙРОФИЗИОЛОГИЧЕСКАЯ ОЦЕНКА РЕАКТИВНОСТИ ЦЕНТРАЛЬНОЙ НЕРВНОЙ СИСТЕМЫ В ОТВЕТ НА ФАРМАКОЛОГИЧЕСКОЕ ВОЗДЕЙСТВИЕ ПРИ ОСТРОЙ ЦЕРЕБРАЛЬНОЙ НЕДОСТАТОЧНОСТИ РАЗЛИЧНОГО ГЕНЕЗА
}

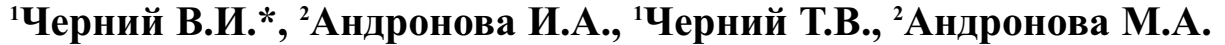 \\ ${ }^{\prime}$ Государственное научное учреждение «Научно-практический иентр профилактической \\ и клинической медициныл Государственного управления делами, Киев, Украина; \\ 'Донецкий национальный медицинский университет им. М.Горького, Донеик, Украина
}

Одной из задач современной клинической нейрофизиологии является выявление и количественная оценка изменений электроэнцефалографии (ЭЭГ) при внешних воздействиях, что необходимо для понимания механизмов формирования ответных реакций мозга на нейропротективную фармакотерапию при острой церебральной недостаточности. Целью исследования являлась количественная оценка изменений ЭЭГ при раздражениях (фармакологическое воздействие), которые недоступны при визуальном анализе, для выявления нейрофизиологических механизмов формирования ответных реакций мозга. Материал и методы. Обследовано 86 больных - 46 пациентов, перенесших ишемический инсульт и 40 больных с тяжелой черепно-мозговой травмой, находившихся на лечении в нейрохирургическом центре Донецкого областного клинического территориального медицинского объединения в период за 2005-2011 гг. Проводили компьютерную томографию и магнитнорезонансную томографию головного мозга, транскраниальную ультразвуковую допплерографию, ЭЭГ. Исследования проводили до введения и на фоне максимальной концентрации препарата Тиоцетам в плазме (через 30 минут) в суточной дозе 15, 20 и 30 мл на протяжении 7 дней. Результаты. Была разработана классификация реактивности - три типа (13 подгрупп) реакций центральной нервной системы (ЦНС) на фармакологическое воздействие - введение различных ноотропных препаратов. І тип - отсутствие достоверных изменений показателей абсолютной спектральной мощности и интегральных коэффициентов - является прогностически неблагоприятный. Реакции II типа отражают изменения корково-подкорковых взаимодействий в ответ на фармакологическое воздействие. Реакции III типа отражают изменения взаимодействий на уровне коры мозга. Факторами, влияющими на эффективность интенсивной терапии Тиоцетамом, являются функциональная сохранность церебральных структур, нейромедиаторных и метаболических механизмов, участвующих в функциональном ответе, и доза Тиоцетама. Выводы. Используя классификацию типов реакции ЦНС в ответ на введение любого нейротропного препарата, возможно оценить адекватность применяемой дозы препарата и необходимость ее коррекции.

Ключевые слова: мозговой инсульт, черепно-мозговая травма, количественная электроэнцефалография, спектральная мощность, типы реакции ЦНС.

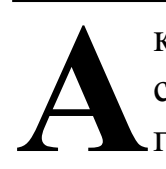

ктуальность темы. Оценка реактивных сдвигов, выявляемых на электроэнцефалографии (ЭЭГ) в ответ на различного рода афферентные раздражения, расширяет представления о характере и формировании биоэлектрических ритмов мозга, о закономерностях их межцентральных отношений и позволяет правильно подойти к пониманию механизмов, лежащих в основе ответных реакций ЭЭГ на внешние сигналы $[1,2]$. Рядом исследований было показано, что функциональные нагрузки вызывают изменения амплитудно-частотных характеристик ЭЭГ человека [2].

Использование математических методов анализа ЭЭГ дает возможность количественно оценить степень этих изменений и проследить за характером реагирования отдельных частотных составляющих ЭЭГ и их межцентральных отношений $[3,4]$. В современных условиях метод ЭЭГ дополнился и преобразился благодаря внедрению компьютерных технологий [2,5]. Одной из *e-mail: vladimircherniy3@gmail.com задач современной клинической нейрофизиологии является выявление и количественная оценка изменений ЭЭГ при внешних воздействиях, чтобы приблизиться к пониманию механизмов формирования ответных реакций мозга во время нейропротективной фармакотерапии при острой церебральной недостаточности (ОЦН).

Целью данного исследования являлась количественная оценка изменений ЭЭГ при раздражениях (фармакологическое воздействие), недоступных при визуальном анализе, для выявления нейрофизиологических механизмов формирования ответных реакций мозга.

Материал и методы исследования. Обследовано 86 больных, которые были разделены на 2 группы. В первую группу входили 46 пациентов, перенесших ишемический инсульт (ИИ) - 26 мужчин и 20 женщин, в возрасте от 43 до 62 лет. Вторая группа состояла из 40 больных (19 мужчин и 21 женщин, в возрасте от 30 до 50 лет) с череп- 
но-мозговой травмой (ЧМТ), находящихся на лечении в нейрохирургическом центре Донецкого областного клинического территориального медицинского объединения (ДОКТМО) в период за 2005-2011 гг. Летальность в группе больных с ИИ составила $13,04 \%$, а в группе с ЧМТ - $14,7 \%$. Степень неврологического дефицита у больных с ИИ определялась по Скандинавской шкале инсультов и составила 2-12 балов [6]. Глубину коматозного состояния определяли с помощью шкалы комы Глазго (ШКГ) [4]. При поступлении в отделение первичная оценка степени нарушения сознания по ШКГ в первой группе составила 9-12 баллов, а во второй группе - 6-11 баллов.

Проводили компьютерную томографию (КТ) и магнитно-резонансную томографию (МРТ) головного мозга, транскраниальную ультразвуковую допплерографию (УЗДГ), ЭЭГ.

В качестве нейропротектора был выбран препарат Тиоцетам, исследован его дозозависимый эффект. Исследования проводили до введения Тиоцетама, на фоне максимальной концентрации препарата в плазме (через 30 минут после введения препарата) и после завершения курса лечения. Тиоцетам вводили внутривенно капельно с первых суток поступления в отделение нейрохирургической интенсивной терапии (ОНХИТ) в суточной дозе 15, 20 и 30 мл на 150 мл физиологического раствора, в течении часа, на протяжении 7 дней $[7,8]$.

Для оценки функции ЦНС проводили клини- ческое и неврологическое обследование [9]. Регистрация биопотенциалов мозга осуществлялась с помощью нейрофизиологического комплекса, состоящего из 8-канального электроэнцефалографа фирмы Medicor, персонального компьютера IBM РC АТ с аналогово-цифровым преобразователем и специальным программным обеспечением "Brain mapping" для хранения и обработки электроэнцефалограмм.

Изучали показатели абсолютной мощности (AМ, мкВ $/ \sqrt{ } \Gamma ц)$, относительной мощности (\%) для $\delta$ - (1-4 Гц), $\theta$ - (5-7 Гц), $\alpha-(8-12$ Гц), $\alpha 1-(9-11$ Гц), $\beta 1$ - (13-20 Гц), $\beta 2-(20-30$ Гц) частотных диапазонов ЭЭГ. Для объективной оценки ЭЭГ использован метод интегрального количественного анализа ЭЭГ-паттерна [7]. Были разработаны интегральные коэффициенты, которые дают возможность провести оценку спектральной мощности всех частотных диапазонов ЭЭГ и определить значимость отдельных частотных спектров ЭЭГ в формировании целостного паттерна ЭЭГ [10].

Реактивность (Reactivity) - подверженность отдельных ЭЭГ ритмов или ЭЭГ в целом изменяться под влиянием сенсорной стимуляции или других физиологических воздействий ЦНС $[2,3,7]$, оценивали по изменению показателей абсолютной спектр-мощности - absolute spectral power (ASP) (в \%) и интегральных коэффициентов (ИК) ЭЭГ-паттерна у конкретного пациента в ответ на введение нейротропного препарата (ф. 1):

$$
\mathrm{R}=\text { Реактивность }=\frac{\text { Фоновыйпоказательпослевведенияпрепарата }}{\text { Фоновыйпоказательдовведенияпрепарата }} \times 100-100 \text { (ф.1) }
$$

Собственные результаты и их обсуждение: На основании анализа записей ЭЭГ у 86 больных с ОЦН различного генеза до и после введения нейротропного препарата - Тиоцетама [7] были выявлены типы реакции ЦНС на фармакологическое воздействие - всего 596 электроэнцефалограмм.

Из 596 ЭЭГ (1192 типов реакций, по 596 справа и слева) исследований суммарная спектральная мощность практически не изменялась (диапазон изменений $\pm 10 \%)$ в 118 случаях (6\% всех изменений). Такие изменения были отнесены к І типу реакций ЦНС (рис. 1).

В 913 случаях (45\% всех ЭЭГ изменений) суммарная спектральная мощность умеренно увеличивалась в диапазоне от 10 до 30 \%. В 513 случаях (25\% всех ЭЭГ изменений) суммарная спектральная мощность умеренно снижалась от -10 до -30\%. Подобные изменения были отнесены к III типу реакций ЦНС, к так называемым реакциям перераспределения мощности.

В 274 случаях (14\% всех ЭЭГ изменений) суммарная спектральная мощность значительно увеличивалась - более чем на 30\%. В 204 случаях (10\% всех ЭЭГ изменений) суммарная спектральная мощность значительно снижалась - более чем на $-30 \%$. Такие изменения были отнесены к II типу реакций ЦНС, причем, снижение СМ - II 2 подтип, а увеличение - II 1 подтип реакций ЦНС. 


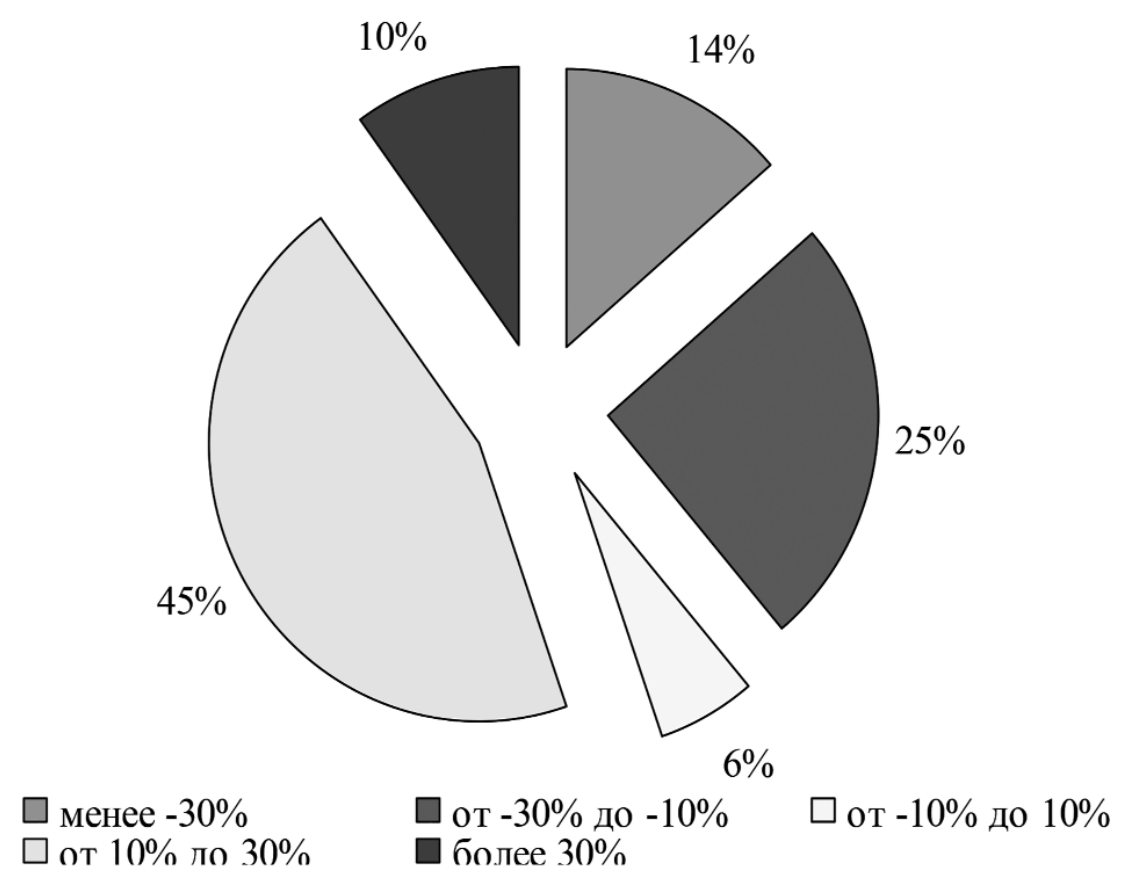

Рис. 1. Число изменений показателей суммарной абсолютной спектральной мощности у пациентов с мозговым инсультом и тяжелой черепно-мозговой травмой.

Затем с помощью корреляционного анализа изменений (R) показателей абсолютной спектрмощности и интегральных коэффициентов ЭЭГпаттерна до и после фармакологического воздействия были установлены взаимно некоррелируе-

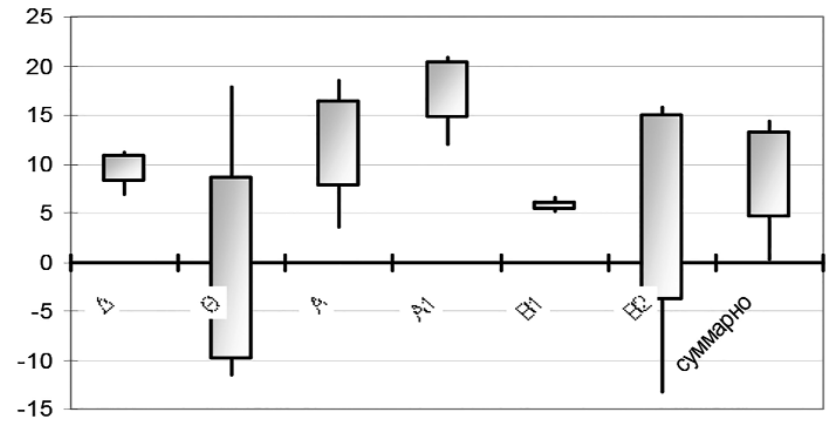

мые варианты этих изменений - это и были типы реакции ЦНС на фармакологическое воздействие.

I тип (рис. 2) характеризовался отсутствием изменений (не более $\pm 10 \%$ ) показателей суммарной ASP и интегральных коэффициентов.

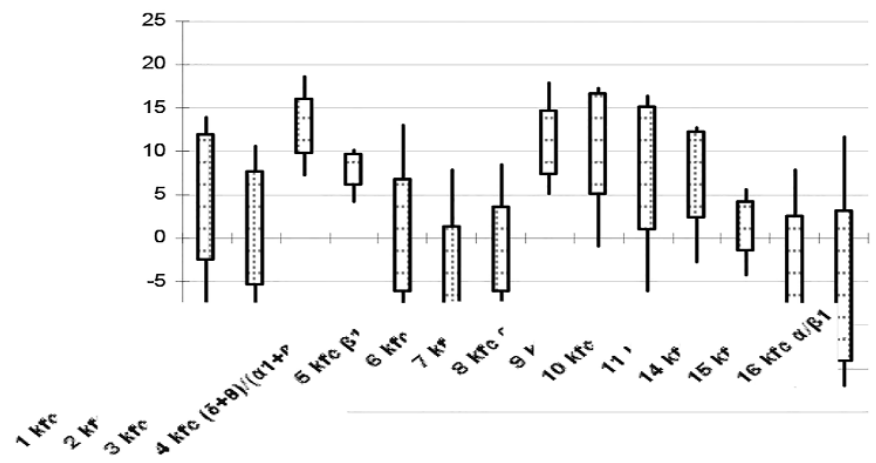

Рис. 2. Изменения абсолютной спектральной мощности (а) и интегральных коэффициентов (б) при реакции ЦНС I типа.

Для II типа реакций свойственно выраженное (статистически значимое - более $\pm 30 \%$ ) изменение - рост или снижение - уровня суммарной ЭЭГ- мощности (CM). Соответственно с увеличением или снижением данного показателя выделены две группы реакций ЦНС у данной категории пациентов после введения Тиоцетама.

При увеличении суммарной спектр-мощности ЭЭГ (II тип, 1-я группа реакций), безусловно, прямо пропорционально связанным с аугментацией -уве- личением амплитуды электрической активности $[11,12]$. Чаще всего отмечались следующие закономерности изменений абсолютной спектральной мощности во всех исследуемых диапазонах. Рост CM преимущественно за счет увеличения ASP медленноволновых «патологических» дельта- и тетадиапазонов (рис. 3) с умеренной активацией $\alpha$ ритма (1а подгруппа (ПГ)) и увеличение СМ за счет повышения ASP дельта-, тета- и $\beta 2$-активности (рис. 4) при стабильности показателей $\alpha$ - диапазо- 
на (1б ПГ) (рис. 5). Для ПГ 1б характерно увеличение суммарной ЭЭГ мощности с ростом $\alpha$-мощности при синхронной редукции высокочастотного бета 2- и «патологического» дельта-ритма. Для II 1г ПГ (рис. 6) было характерно увеличение суммарной ЭЭГ мощности с ростом $\beta 2$-мощности при синхронной редукции или отсутствии значимых изменений, как «патологических» дельта- и тета-ритмов.

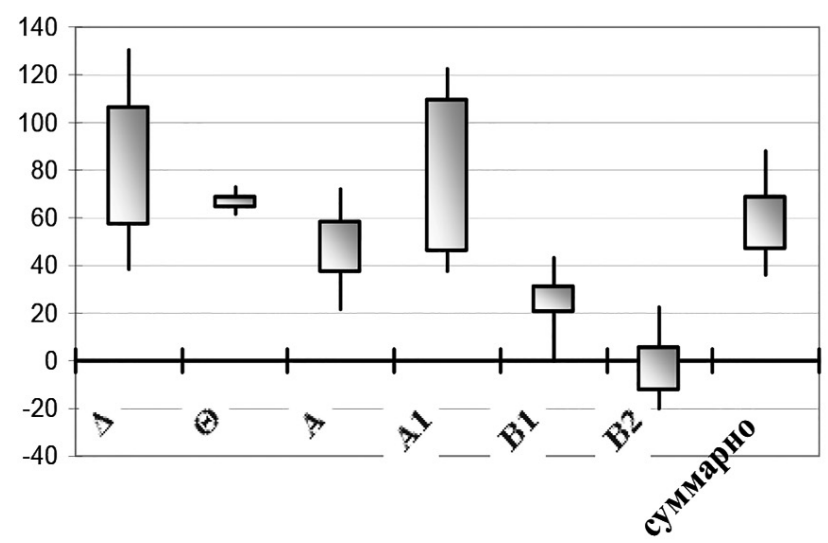

Следует отметить, что реакции ЦНС II 1а подгруппы (ПГ) (рис. 3.) сопровождаются преимущественной активацией $\alpha 1$-поддиапазона и перераспределением мощности в $\beta$-частотном диапазоне с преобладанием низкочастотного $\beta 1$-ритма. Для этой подгруппы реакций характерно увеличение уровней 1-го, 2-го, 9-го ИК. Максимального роста достигают показатели 5-го и 15-го ИК.

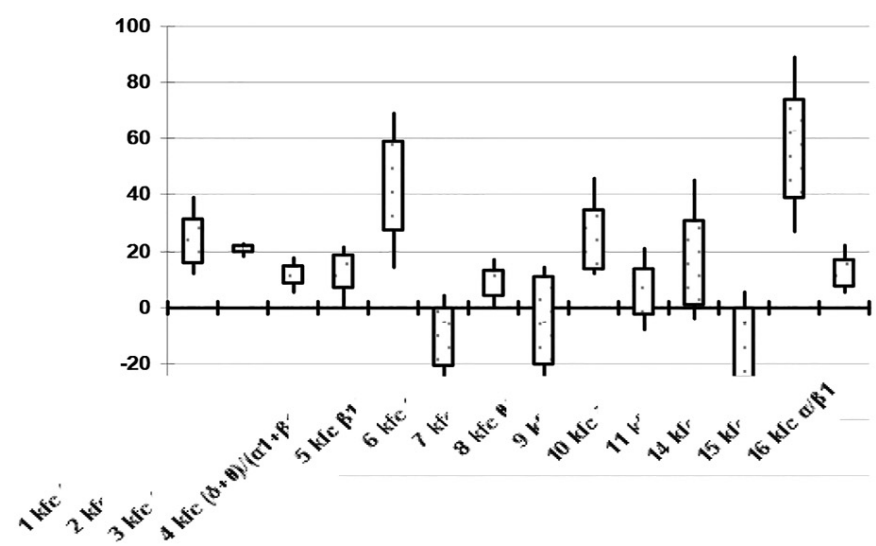

Рис. 3. Изменения абсолютной спектральной мощности (а) и интегральных коэффициентов (б) при реакции ЦНС II типа 1а подгруппы.

В подгруппе реакций II 16 с увеличением CM за счет повышения ASP дельта-, тета- и $\beta 2$ активности (рис. 4.) показатель ASP $\alpha$-диапазона стабилен, но отмечаются тенденции к угнетению $\alpha 1$-ритма. Особенностями реакций II 16

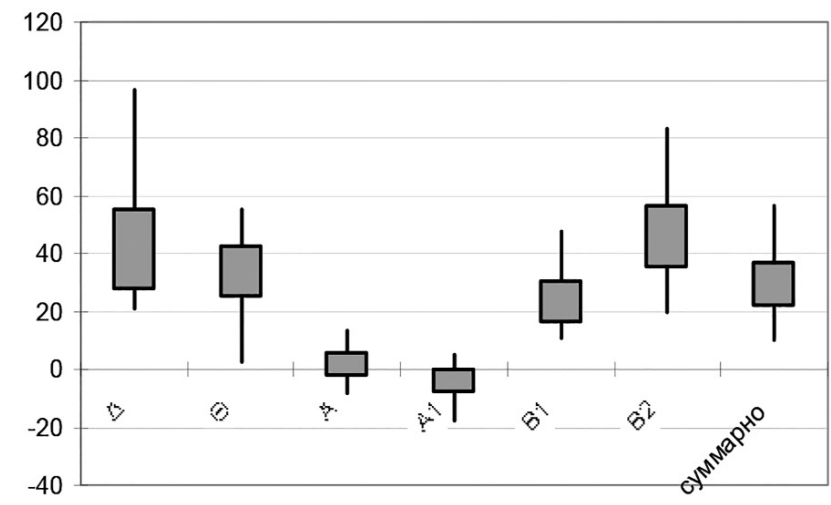

ПГ следует считать выраженный рост уровней 3-го, 4-го, 8-го, 10-го, снижение 5-го и вариабельность изменений 15-го ИК, связанная в большей мере с активацией «быстрого» бетаритма.

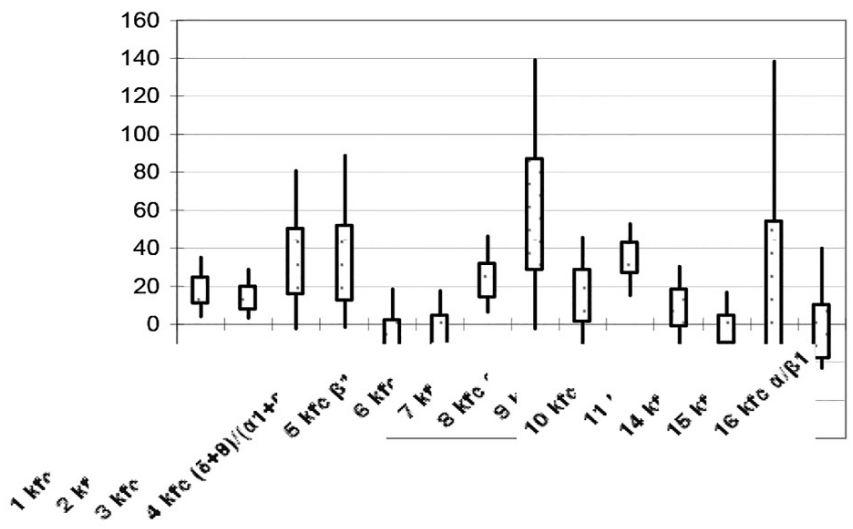

Рис. 4. Изменения абсолютной спектральной мощности (а) и интегральных коэффициентов (б) при реакции ЦНС ІІ типа 1 б подгруппы.

В следующих исследованиях было выявлено, что первое введение препарата Энтропа [13] в дозе 100 мг характеризовалось формированием двух вариантов «ответа» ЦНС, которое не встречалось при применении Тиоцетама.

Интересна реакция II 1в ПГ, для которой характерны уменьшение дезорганизации ЭЭГ паттерна за счет активации $\alpha$-ритма и снижение активирующих подкорковых влияний на кору (рис. 5). Такие реакции были выявлены у 3-х исследуемых в ответ на введение Энтропа в дозе более 100 мг в сутки, всегда асимметричны. 


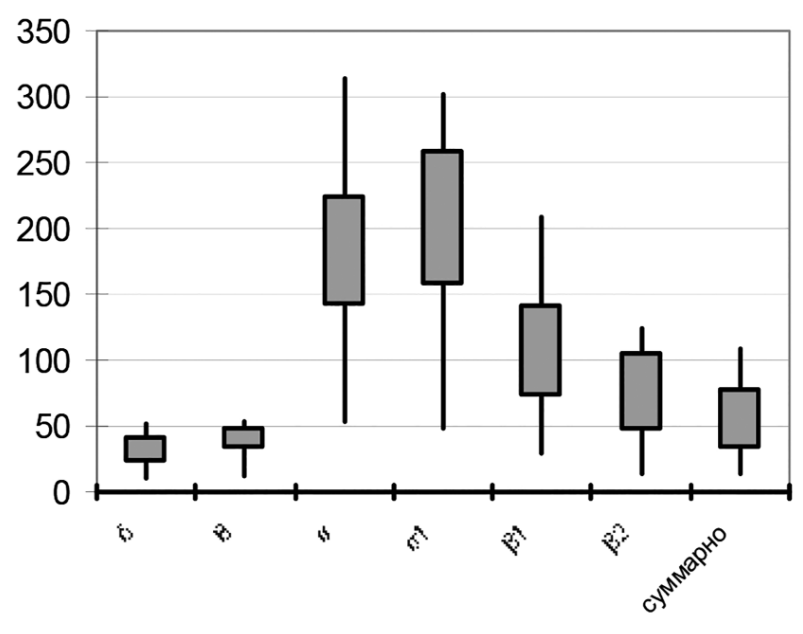

a

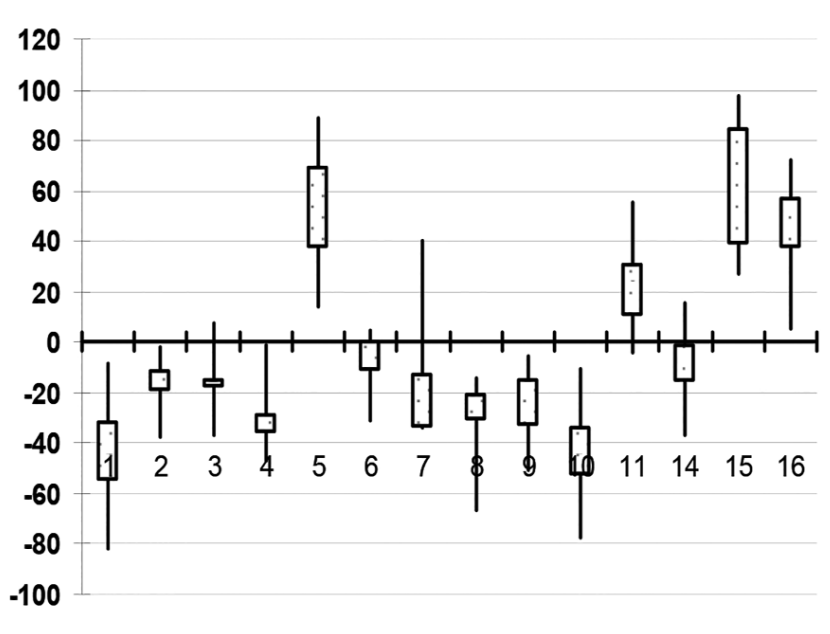

б

Рис. 5. Изменения абсолютной спектральной мощности (а) и интегральных коэффициентов (б) при реакции ЦНС II типа 1в подгруппы.

Для симметричных реакций II 1г подгруп- высокочастотного $\beta$ 2-диапазона (20-30 Гц) пы было типично увеличение уровня суммар- во всех исследуемых областях коры, что ной ЭЭГ-мощности за счет значительного являлось ЭЭГ коррелятом корковой ирритароста абсолютной спектр-мощности (ASP) ции (рис. 6).
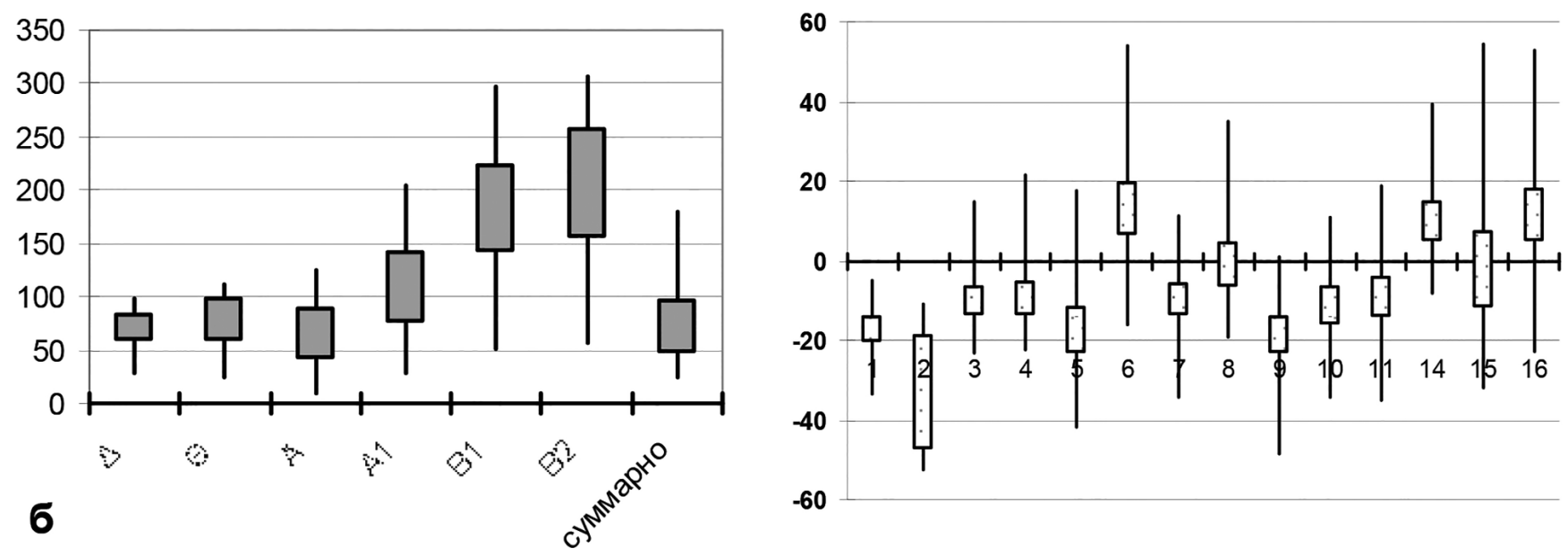

Рис. 6. Изменения абсолютной спектральной мощности (а) и интегральных коэффициентов (б) при реакции II типа 1г подгруппы.

При снижении СМ (II тип, 2-я группа реакций), прямо пропорционально связанным с ослаблением - Attenuation - снижением амплитуды электрической активности в ответ на физиологические стимулы или электрическое раздражение мозга, которая в этом случае называется блокированием $[2,11,12]$, выявлены следующие закономерности изменений ASP.

Уменьшение СМ преимущественно за счет угнетения медленноволновых $\delta$ - и $\theta$-ритмов с умеренной редукцией $\alpha$-активности (II $2 \mathrm{a}$ под- группа), причём такая десинхронизация ЭЭГ связана с ростом активности ретикулярной формации среднего и продолговатого мозга. И снижение CM за счет ASP всех частотных ЭЭГ-диапазонов (II $2 б$ подгруппа), причем такое блокирование отражает активацию ретикулярной формации, прежде всего, ствола мозга и приводит к снижению коркового компонента ЭЭГ у пациентов с ОЦН различного генеза при повышении общего уровня функциональной активности мозга. 
Для реакций II 2а подгруппы (рис. 7.) характерно снижение уровней большинства ИК, наиболее показательно уменьшение уровней 1-4-го, 11-го ИК и увеличение «обратного» ему 6-го ИК, что связано с выра-

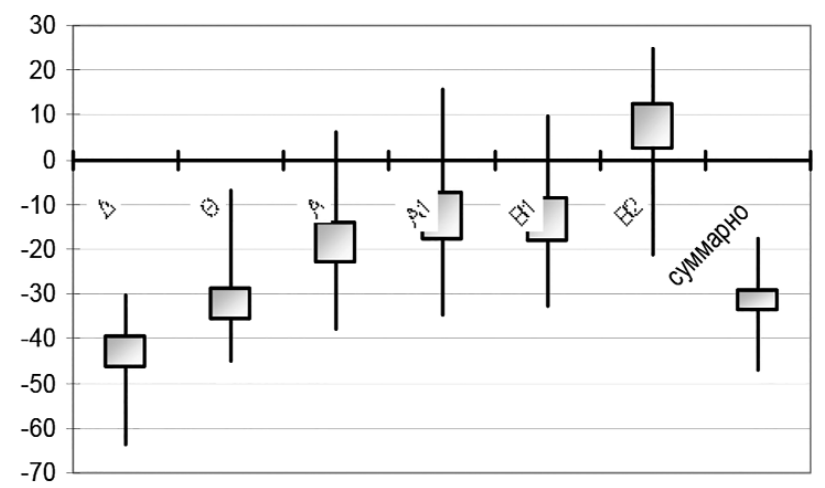

женным угнетением $\delta$-ритма. Следует отметить значительную вариабельность изменений ASP al-поддиапазона, что предопределяет достаточно широкий «разброс» значений 14-го и 16-го ИК.

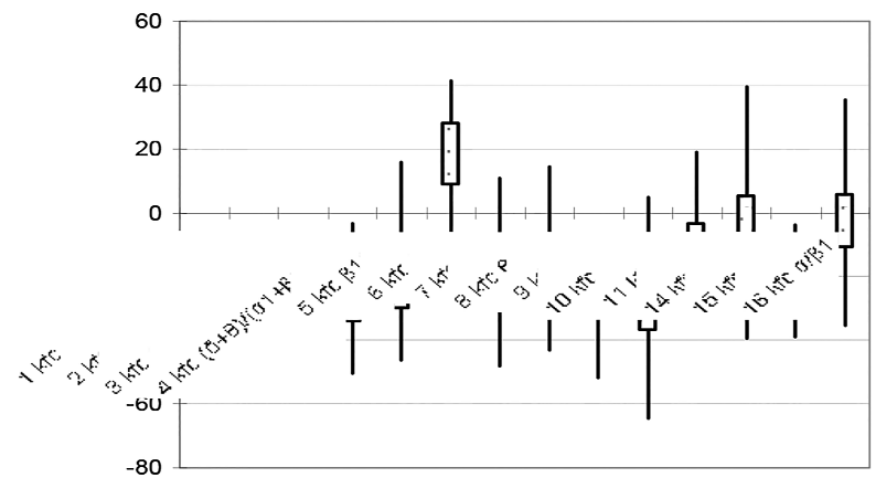

Рис. 7. Изменения абсолютной спектральной мощности (а) и интегральных коэффициентов (б) при реакции ЦНС ІІ типа 2а подгруппы.

Синхронность снижения ASP всех ЭЭГ-диапазонов, типичная для реакций II 26 ПГ (рис.8.) предопределяет стабильность показателей ИК.

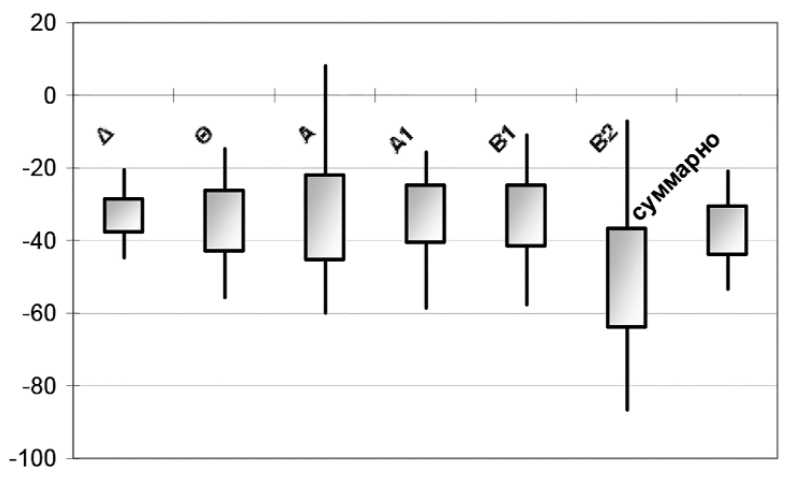

Исключения составляют только 5-й и 15-й ИК, рост которых обусловлен угнетением высокочастотного бета-ритма.

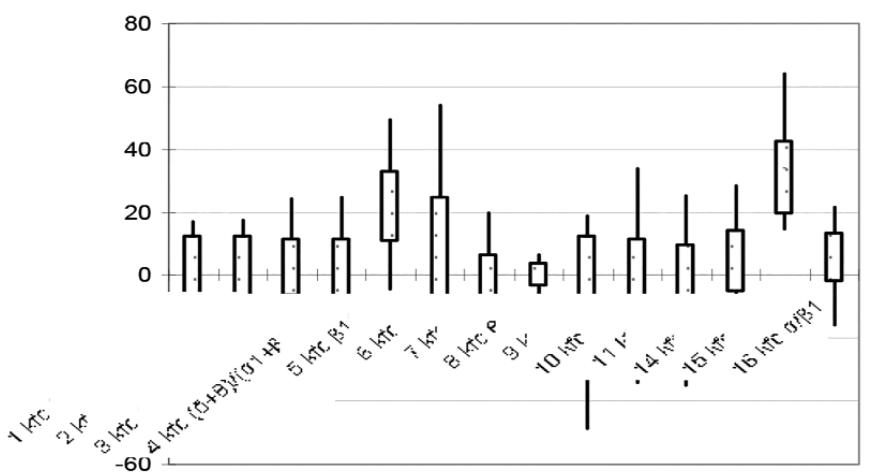

Рис. 8. Изменения абсолютной спектральной мощности (а) и интегральных коэффициентов (б) при реакции ЦНС ІІ типа 2 подгруппы.

Реакции II типа, с обязательным ростом (1 группа реакций) или снижением (2 группа реакций) $\mathrm{CM}$, на наш взгляд, отражают изменения степени активирующих воздействий на кору со стороны подкорковых структур (ретикулярной формации), когда увеличение суммарной СМ свидетельствует о снижении активирующих процессов стволового и активации вышележащих уровней неспецифической регуляции, а снижение - об активации ретикулярных стволовых (или среднего мозга) подкорковых влияний с умеренным «снятием» влияний вышерасположенных структур неспецифической регуляции - таламуса и диэнцефальных образований при формирование ЭЭГ-паттернов.

Следует отметить, что реакция II 1а подгруппы проявляется в ситуациях, когда таламический ЭЭГ-ритм дельта-диапазона генерируется отдельной клеткой таламуса на самом глубоком уровне ее гиперполяризации, тета- диапазона на менее глубоком гиперполяризационном уровне [14] или дельта-ритм корковой генерации усиливается при разобщении корковых и таламических структур, но при обязательном подавлении сигналов (гипофункции) от восходящей активационной системы ствола мозга [14]. 
Реакция II 16 подгруппы также формируется при снижении функции активирующей системы стволового уровня и таламической гиперактивации при нарушении «внутриталамических» взаимодействий - между неспецифическими ядрами таламуса, но это сопровождается ростом метаболической активности корковых структур и, возможно, проявлением выраженной ГАМКергической корковой реакции.

Реакция II 1в ПГ отражает выраженную генерацию регулярно действующим таламусом $\alpha$ ритма при адекватном взаимодействии между неспецифическими ядрами таламуса - синхронизированное торможение ретикулярными нейронами (вентральный таламус - ретикулярное ядро) таламокортикальных нейронов при их относительной деполяризации.

Реакция II 1г ПГ - значительная $\beta$ 2-синхронизация, таким образом, отражает процессы выраженной корковой ирритации («сверхактивации»), что объясняется реакцией на сильную активацию корковых нейронных сетей, когда тормозные (ГАМК-ергические) нейроны получают достаточное возбуждение от внешних входов (таламокортикальные и стволо-кортикальные воздействия) и рядом расположенных возбуждающих корковых нейронов. Такое торможение происходит циклично, и каждый цикл цикл $\beta$ - активности [4,14].

Таким образом, реакции II типа описывают значимую реализацию фармакологического ответа на конкретный нейротропный препарат на стволовом (II 26 подгруппа) уровне, на уровне ретикулярной формации среднего и продолговатого мозга (II 2a подгруппа), на уровне неадекватно функционирующих неспецифических ядер таламуса при выраженной функциональной недостаточности ствола (II 1a ПГ), на уровне разобщенно действующих неспецифических ядер таламуса при выраженной стволовой недостаточности и при значительной активации таламо-кортикальных взаимодействий с ростом метаболической активности корковых структур (II 16 ПГ), на уровне таламокортикальных нейронов при их относительной деполяризации при адекватном взаимодействии между неспецифическими ядрами таламуса (II 1в ПГ), на уровне корковых тормозных нейронов, которые полу- чают достаточное возбуждение от внешних входов (таламокортикальные и стволо-кортикальные воздействия) (II 1г ПГ).

III тип реакций ЦНС характеризуется умеренными или незначительными изменениями (менее $\pm 30 \%$ ) CM, а изменения ЭЭГ-паттерна связаны с перераспределением спектральной мощности, с активацией ЭЭГ-ритма одного частотного диапазона за счет угнетения другого. Отмечаются следующие варианты перераспределения активности: с увеличением мощности медленно-волновых, так называемых, «патологических» ритмов (III тип, 1-я группа), с преимущественной активацией $\alpha$-ритма (III тип, 2я группа) и с ростом уровня мощности $\beta$-диапазона (III тип, 3-я группа).

Интегративная деятельность мозга основана на кооперативной деятельности множества функциональных единиц - “колонок”, “нейронных ансамблей”, “нейронных модулей”, в пределах которых осуществляется циркуляция возбуждения, отраженного в поверхностно регистрируемых колебаниях ЭЭГ, работающих по вероятностно-статистическому принципу с попеременным пространственно-временным распределением [2,10]. Причем циркуляция импульсов внутри этих объединений и создает циклические контуры связи $[4,14]$, поэтому ЭЭГ чувствительна как к радиальным, так и тангенциальным (поверхностным) источникам возбуждения [15]. Исходя из этого изменения ЭЭГ, относящиеся к III типу, при ОЦН различного генеза связаны с морфофункциональными перестройками на корковом уровне. Смещение пика ЭЭГ активности в медленноволновой дельтачастотный диапазон может быть связано с активацией нейроглиальной популяции, метаболизма и церебрального энергетического обмена, так как медленные биоэлектрические процессы мозга частотой ниже 1 Гц рассматриваются в литературе как их корреляты $[2,4]$. Активацию медленной активности более высокой частоты дельта-диапазона традиционно связывают со снижением уровня оксигенации коры, чаще сосудистого генеза, связанного, как с падением, так и с выраженным ростом АД [9]. Смещение пика спектрмощности в диапазон тета-ритма реализуется через системы нейромедиаторов: тета-актив- 
ность 6-7,5 Гц связана с холинергической, 5-6 Гц - серотонинергической, а 4-5 Гц - адренергической активацией $[2,4,14]$.

Умеренная активация $\alpha$-ритма коркового генеза, который является ритмом состояния «холостого хода» корковых областей, отражает процессы снижения метаболической активности коры. Однако, данная активность, по мнению Р.И.Мачинской [2], играет важную роль в объединении структур мозга для различных видов сенсорной или когнитивной деятельности, формируя динамическую основу их функционального взаимодействия, как бы подготавливая корковые структуры к осуществлению процессов мышления. Также смещение пика ЭЭГ-активности в область высокочастотного $\alpha$-ритма (11-12 Гц) может быть связано с деятельностью дофаминэргической системы $[2,4,14]$. Превалирование в ЭЭГ $\alpha$ и $\beta$ - частот и снижение пространственной

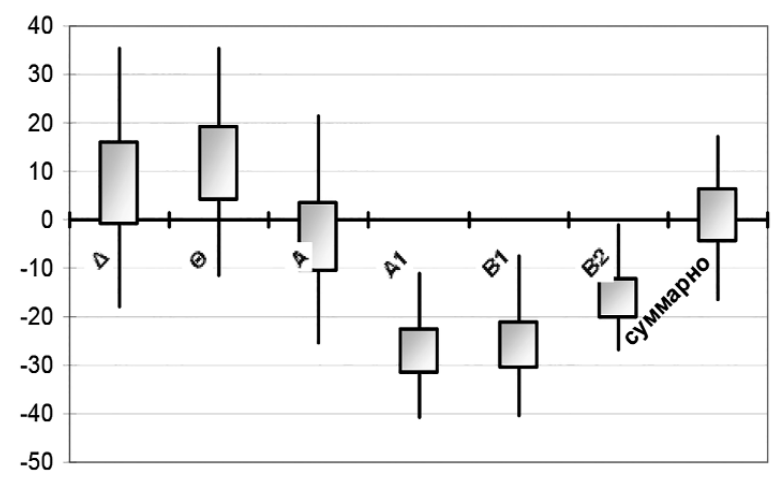

синхронизации биопотенциалов, напротив, связаны с формированием более адекватных условий протекания этих процессов в состоянии бодрствования. Поэтому перераспределение мощности в диапазон $\beta$-ритма является отражением когнитивных процессов в коре и, также, связанные с ними выраженные процессы активации ГАМКергических и серотонинэргических нейромедиаторных - преимущественно тормозных корковых процессов [2,4,14].

Одним из наиболее часто встречаемых типов реакций является III 1a, при которой отмечается активация медленноволновых $\delta$ - и $\theta$-ритмов за счет угнетения $\alpha 1$-активности (рис. 9.). Часто такое замещение $\alpha 1$-ритма сопровождается снижением уровня преимущественно низкочастотного компонента бета- активности. Для III 1a ПГ реакций характерно увеличение уровней 3-го, 4го, 8-го, 10-го 14-го и 16-го ИК.

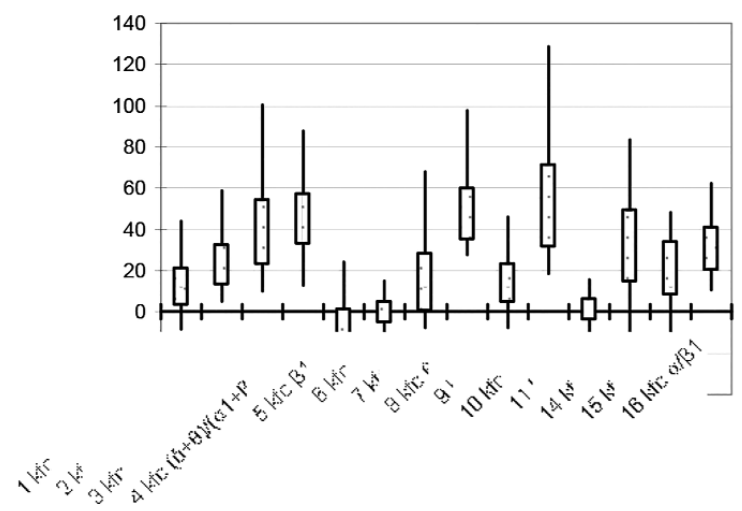

Рис. 9. Изменения абсолютной спектральной мощности (а) и интегральных коэффициентов (б) при реакции ЦНС III типа 1а подгруппы.

Интересна реакция перераспределения мощности с синхронной активацией $\delta$ - и $\beta$-ритмов за счет угнетения всех частотных диапазонов $\alpha$-активно-

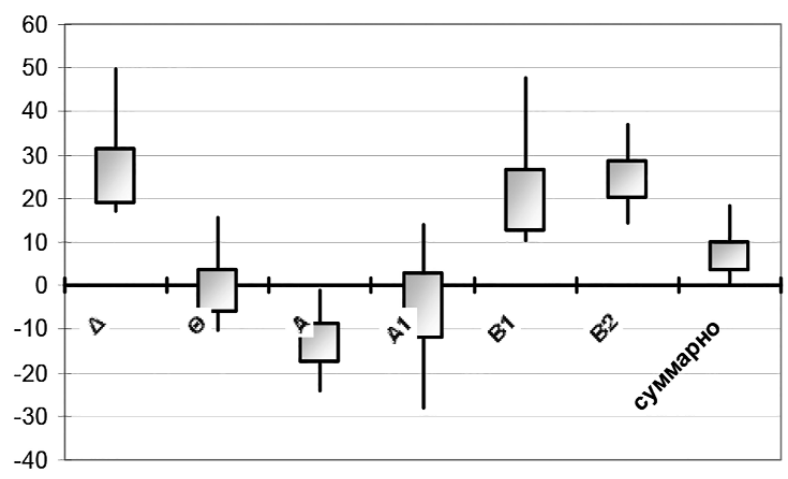

сти (III 1б ПГ) (рис. 10). Для этой подгруппы реакций характерно увеличение уровней 9-го, 10-го и 11-го ИК и снижение уровня 6-го, 15-го и 16-го ИК.

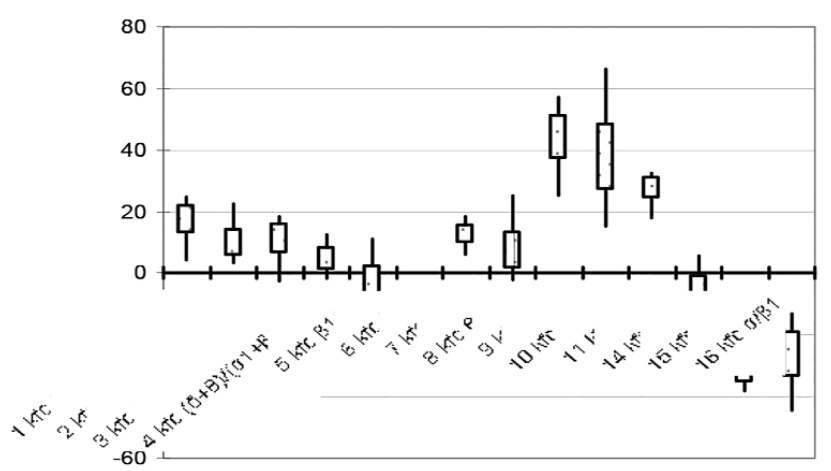

Рис. 10. Изменения абсолютной спектральной мощности (а) и интегральных коэффициентов (б) при реакции ЦНС III типа 1 подгруппы. 
Реакция перераспределения ЭЭГ мощности с активацией её $\alpha$ - и $\beta 2$-диапазонов («нормальных» ритмов ЭЭГ) за счет редукции $\delta$ - активности (III 2a) представлена на рис. 11. Для этой подгруппы реакций характерно снижение уровней 1-го, 2-го, 5-го, 7-го и наиболее выраженное - 9-го ИК одновременно с ростом 14-го и 16-го ИК. Следует отметить, что рост спектр-мощности $\alpha$-диапазона связан с активацией частотных полос «медленного» (8-9 Гц) и «быстрого» (11-12 Гц) $\alpha$-ритма при стабильности $\alpha 1$-поддиапазона.

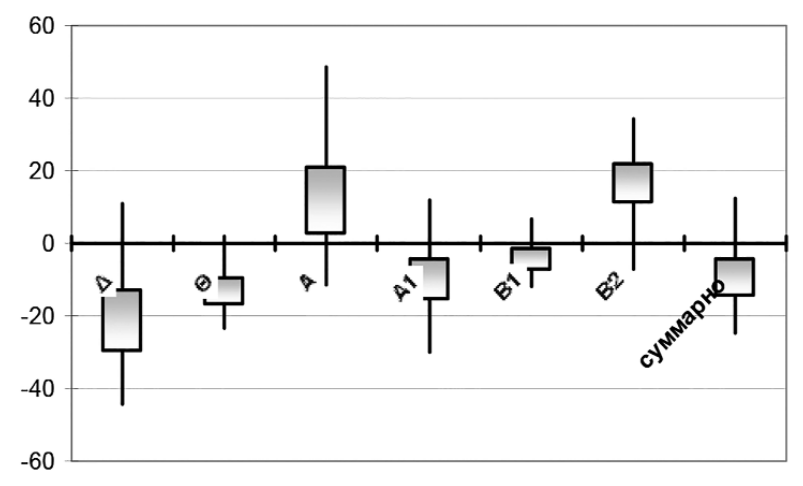

Перераспределение ЭЭГ-активности с увеличением $\alpha$ мощности за счет синхронной редукции высокочастотного бета 2- и «патологического» дельта-ритмов (III тип 26 подгруппа) характеризуется умеренным снижением 7-10-го ИК, тенденцией к росту 5-го и значительным увеличением уровня 15-го ИК (рис. 12). Следует отметить тенденцию к росту 14-го ИК, свидетельствующую о том, что активация $\alpha$-ритма связана с преимущественным увеличением ASP $\alpha 1$-поддиапазона.

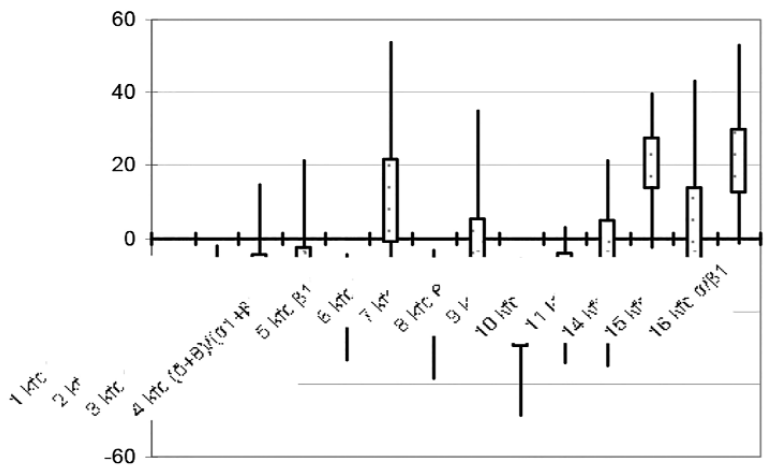

Рис. 11. Изменения абсолютной спектральной мощности (а) и интегральных коэффициентов (б) при реакции ЦНС III типа 2а подгруппы.
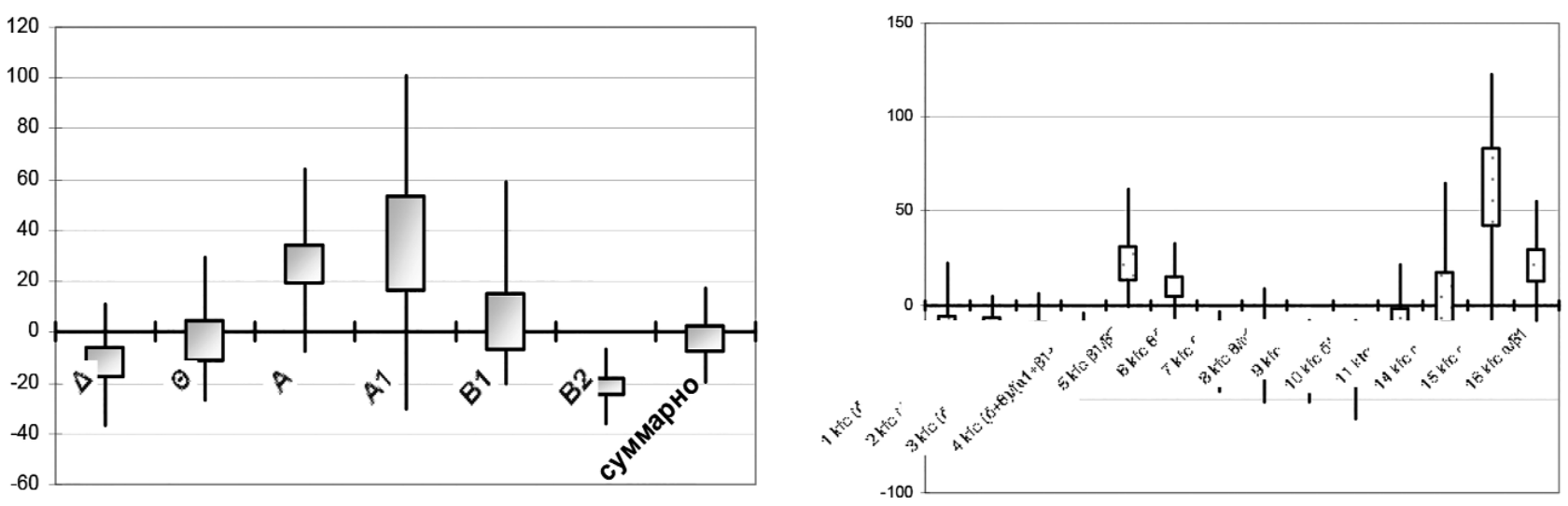

Рис. 12. Изменения абсолютной спектральной мощности (а) и интегральных коэффициентов (б) при реакции ЦНС ІІІ типа 2 п подгруппы.

К 3-й группе реакций перераспределения мощности следует отнести активацию высокочастотного $\beta 2$-ритма за счет редукции $\alpha$-активности (III 3а ПГ) (рис. 13.). Наиболее выраженными изменениями ИК в данной подгруппе реакций является рост 7-го, 9-го ИК и снижение 15-го ИК.

Перераспределение ЭЭГ-активности с увеличением $\beta 2$-мощности за счет редукции $\delta$ ритма (III тип 36 подгруппа) характеризуется тенденцией к снижению 1-2-го, 5-го, 9-го, 10-го, 11-го ИК, тенденцией к росту 6-го, 14-го и 16-го ИК (рис. 14.). Следует отметить, что выявлены преимущественно тенденции к изменениям ИК. Возможно такие реакции следует считать «гипореактивными».

Изучение типов реакции ЦНС в ответ на фармакологическое воздействие дало возможность количественно оценить увеличение или уменьшение дезорганизации ЭЭГ-паттерна и опреде- 

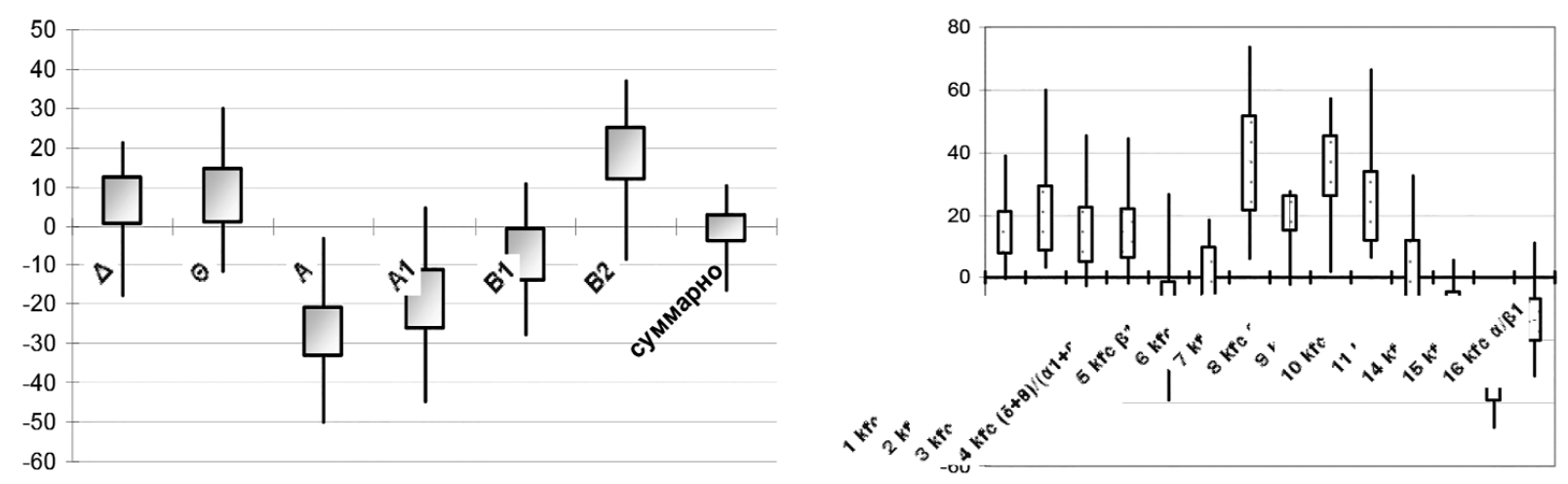

Рис. 13. Изменения абсолютной спектральной мощности (а) и интегральных коэффициентов (б) при реакции ЦНС III типа За подгруппы.
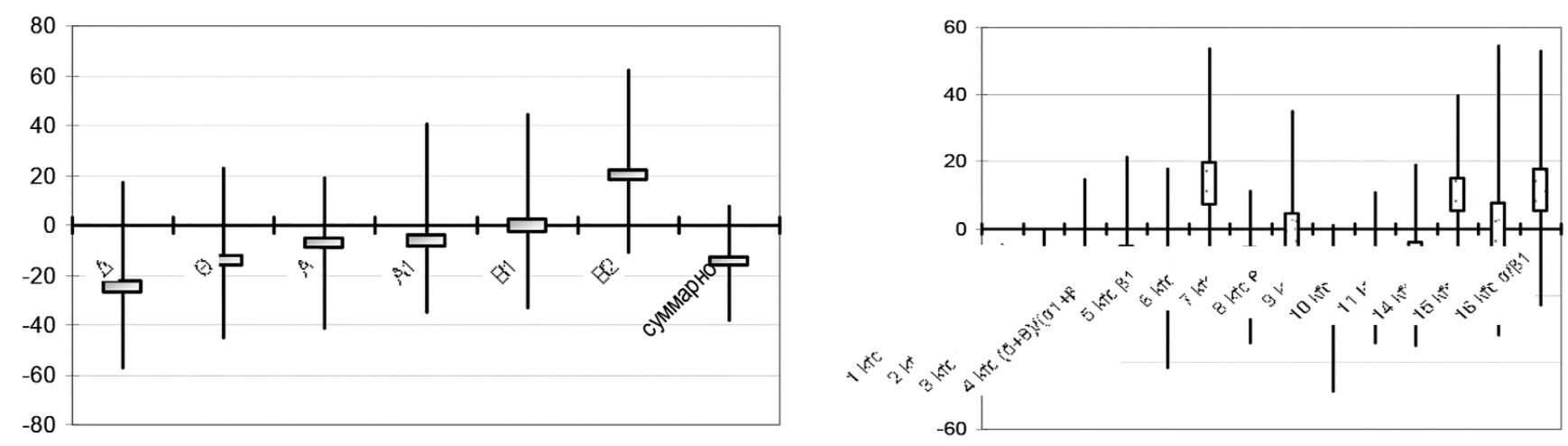

Рис. 14. Изменения абсолютной спектральной мощности (а) и интегральных коэффициентов (б) при реакции ЦНС ІІІ типа $3 б$ подгруппы.

лить уровень нейрофизиологического влияния препарата на мозг (кора-подкорка, кора-кора) (рис.15) [16].

Вышеизложенное позволило прийти к заключению о том, что I тип - отсутствие достоверных изменений показателей абсолютной спектральной мощности и интегральных коэффициентов - прогностически неблагоприятный. II тип 1а подгруппа, 16 подгруппа - увеличение СМ ЭЭГ-паттерна, преимущественно за счет повышения ASP «патологических» $\delta$ и $\theta$ - диапазонов - прогностически неблагоприятный; 1в подгруппа - увеличение СМ ЭЭГ-паттерна, преимущественно за счет повышения ASP $\alpha$-активности - прогностически благоприятный. Реакции II типа отражают изменения корковоподкорковых взаимодействий в ответ на фармакологическое воздействие.

Реакции ЦНС типа II 1а и II 16 ПГ отнесены к прогностически неблагоприятным, т.к. они характеризуются нарастанием дезорганизации ЭЭГ-паттерна за счет недостаточности стволо- вых активирующих влияний с увеличением спектр-мощности патологической, преимущественно $\delta$-волновой активности.

II тип 2а подгруппа, 26 подгруппа - уменьшение СМ ЭЭГ-паттерна, преимущественно за счет угнетения $\delta$ - и $\theta$-ритмов - прогностически благоприятные. Из реакций II типа наиболее благоприятной следует считать $2 \mathrm{a}$ ПГ изменений, отражающих, во-первых, рост активирующих влияний на кору со стороны ретикулярной формации, и, во-вторых, характеризующихся угнетением патологической активности $\delta$ - и $\theta$ диапазонов.

III тип 1а подгруппа, 16 подгруппа - перераспределение мощности за счет активации $\delta$ - и $\theta$ ритмов и угнетении $\alpha 1$-активности - относительно неблагоприятные. Реакции перераспределения III 1а и III 16 подгрупп можно назвать «относительно неблагоприятными», так как они свидетельствуют об относительном восстановлении функции нейронов в условиях обширных морфоструктурных постишемических повреждений 


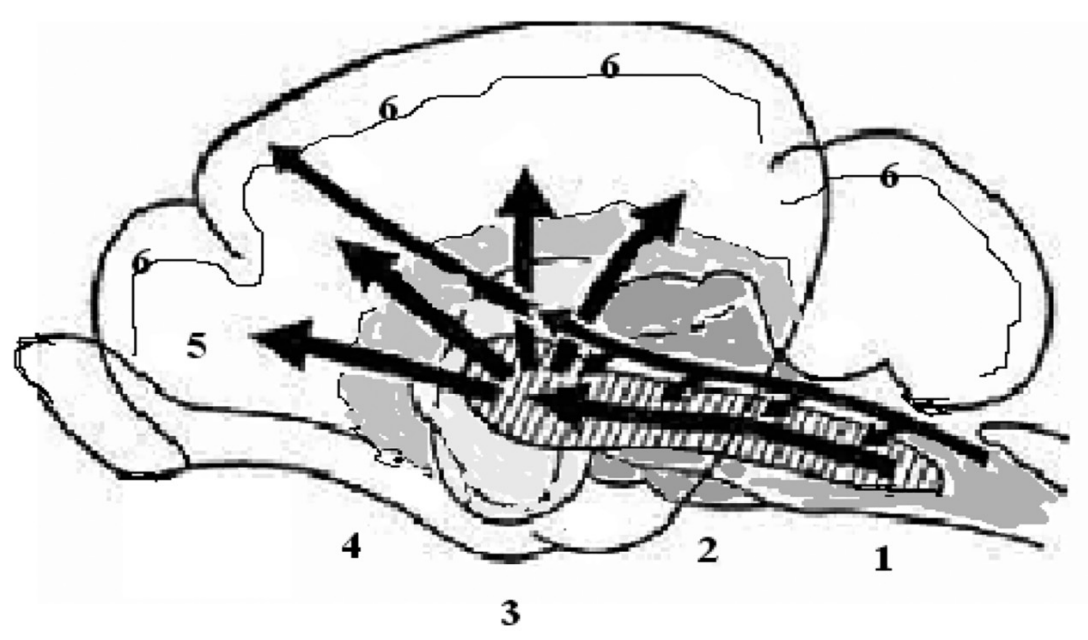

\section{Рис. 15. Уровни приложения фармакологических II типа реакций ЦНС в ответ на введение нейротропных препаратов при острой церебральной недостаточности различного генеза.}

Примечание. 1 - стволовой уровень ретикулярной формации мозга 2 - уровень ретикулярной формации среднего мозга и продолговатого мозга; 3 - таламический уровень неспецифической регуляции мозга; 4 - лимбико-гиппокампальные структуры неспецифической регуляции; 5 - восходящие таламокортикальные связи; 6 - кора больших полушарий мозга.

клеток мозга, но отражают умеренные дезорганизационные ЭЭГ процессы. III тип 2а подгруппа, 26 подгруппа - перераспределение ЭЭГ мощности с активацией мощности $\alpha$ - и $\beta 2$-диапазонов за счет редукции $\delta$-активности - прогностически благоприятные. Реакции III типа- изменения взаимодействий на уровне коры мозга в ответ на фармакологическое воздействие.

Из реакций «перераспределения» мощности (III тип) прогностически благоприятными можно считать III 2а подгруппу изменений, для которой типична активация $\alpha$ - и $\beta 2$-ритмов за счет угнетения $\delta$-активности. Возможно, такие реакции, особенно на стороне поражения, отражают корковые процессы восстановления обратимо поврежденных клеток мозговой ткани, их постсинаптической пропускной способности для высокочастотной стимуляции.

III тип 3а подгруппа, 36 подгруппа - перераспределение ЭЭГ- активности с увеличением $\beta 2$ мощности за счет редукции $\delta$-ритма - прогностически благоприятные. Реакции III типа изменения взаимодействий на уровне коры мозга в ответ на фармакологическое воздействие. Интересны реакции III 3а ПГ, для которых характерно замещение альфа-ритма высокочастотной $\beta 2$ - активностью, что считается ЭЭГкоррелятом перехода от состояния «покоя» к напряжению при умственной деятельности у взрослых.

Факторами, влияющими на эффективность интенсивной терапии Тиоцетамом, являются, с одной стороны, функциональная сохранность церебральных структур, нейромедиаторных и метаболических механизмов, участвующих в функциональном ответе, а с другой - доза Тиоцетама.

Используя определение типа реакции ЦНС в ответ на введение Тиоцетама, возможно оценить адекватность применяемой дозы препарата и необходимость ее коррекции.

Выводы: Сопоставив типы реакций и подгруппы, полученные на введение Тиоцетама, с типами реакций и подгруппами, полученными на введении других нейропротекторов, мы убедились в их неспецифичности и идентичности для любого нейропротектора. Но при исследовании реактивности мозга в ответ на применение различных нейропротекторов мы установили, что на введение фенотропила и Энтропа, кроме описанных типов реакций и подгрупп, существует еще две подгруппы во II типе: II 1в, II 1г. Таким образом, выявлены три типа (13 подгрупп) реакций ЦНС на фармакологическое воздействие - введение различных ноотропных препаратов. 


\section{ЛИТЕРАТУРА - REFERENCES - ӘDӘВIYYАT}

1. Гриндель О.М. Романова Н.В., Зайцев О.С., Воронов В.Г., Скорятина И.Г. Математический анализ электроэнцефалограмм в процессе восстановления сознания после тяжелой черепно-мозговой травмы // Журн неврол и психиат, 2006; 12: с. 47-51.

2. Шарова Е. В. Современные возможности ЭЭГ в анализе функциональных нарушений при тяжелых повреждениях головного мозга // Нейронауки: теоретичні та клінічні аспекти, 2009; Т.5, № 1-2: с. 49-58.

3. Зенков Л.Р., Ронкин М.А. Функциональная диагностика нервных болезней (Руководство для врачей). М.: МЕДпресс-информ, 2004; с. 384-433.,

4. Беленичев И.Ф., Черний В.И. и др. Нейропротекция и нейропластичность / монография. К.: Логос, 2015; 512c. 5. Гриндель О.М., Машеров Е.Л, Воронов В.Г. Методы математического анализа ЭЭГ. В кн. Нейрофизиологические исследования в клинике. М., “Антидор”, 2001; с. 24-38.

6. Гусев Е.И., Скворцова В.И. Ишемия головного мозга, М.:Медицина, 2001; 328 с.

7. Островая Т.В., Черний В.И., Андронова И.А. Исследование реактивности ЦНС в ответ на фармакологическое воздействие (Тиоцетам) // Международный неврологический журнал, 2007; № 2 (12): с. 53-62.

8. Кузнецова С.М., Кузнецов В.В., Воробей М.В. Влияние Тиоцетама на функциональное состояние ЦНС у больных, перенесших ишемический инсульт. // Медична газета «Здоров'я України», 2005; №6: c.1-7.

9. Черний В.И., Калмыкова Т.Н., Черний Е.В., Колесников А.Н., Городник Г.А., Островая Т.В., Андронова И.А.,
Степанюк В.А., Пузик А.А. Интенсивная терапия критических состояний, обусловленных мозговым инсультом / Методические рекомендации, Киев, 2006; 57c.

10. Острова Т.В., Черній В.І., Шевченко А.І. Алгоритм діагностики реактивності ЦНС методами штучного інтелекту. - Д.: ІПШІ МОНУ і НАНУ “Наука і освіта”, 2004; $180 \mathrm{c}$.

11. Зенков Л. Р. Клиническая электроэнцефалография (с элементами эпилептологии) / Таганрог, 1996; 358 с.,

12. Belsh J. M., Chokroverty S., Barabas G. Posterior rhythmic slow activity in EEG after eye closure // Electroencephalogr. clin. neurophysiol., 1983; Vol. 56, № 6: p. 562-568.

13. Черний В.И. Андронова И.А., Черний Т.В., Городник Г.А. Особенности применения ноотропов в комплексной терапии острой церебральной недостаточности различного генеза // Основные направления фармакотерапии в неврологии. Материалы XV Международной конференции 24-26 апреля 2013 г., Судак, с.133-140.

14. Кропотов Ю. Д. Количественная ЭЭГ, когнитивные вызванные потенциалы мозга человека и нейротерапия / Донецк: изд-во Заславский А. Ю., 2010; 512 с.

15. Шарова Е. В., Зайцев О.С., Щекутьев Г.А. и др. ЭЭГ и ВП в прогнозировании развития посттравматических бессознательных состояний после тяжелой травмы мозга // Нейронауки: теоретические и клинические аспекты, 2008; T. 4, № 2: c. 82-89.

16. Островая Т.В., Статінова О.А. Патент на корисну модель № 12188 Україна А61B5/0476. Спосіб визначення реактивності головного мозку. опублік. 16.01.2006 р., Бюл. № 1.

\title{
XÜLASə
}

\section{MÜXTӘLİF GENEZLİ KəSKİN SEREBRAL ÇATMAMAZLIQ ZAMANI MəRKəZI SINIR SISTEMININ REAKTIVLIYININ FARMAKOLOJI TOSIRə CAVABININ NEYROFIZIOLOJI QIYMMTLONDIRILILYSI}

\author{
${ }^{1}$ Çerniy V.İ., ${ }^{2}$ Andronova İ.A., ${ }^{1}$ Çerniy T.V., ${ }^{2}$ Andronova M.A. \\ 'Dövlat İşlar idarasinin "Profilaktik va klinik tababatin elmi-praktik markazi" \\ Dövlat Elmi Müassisasi, Kiyev, Ukrayna; \\ ${ }^{2}$ M.Qorki adına Donesk Milli Tibb Universiteti, Donesk, Ukrayna
}

Müasir klinik neyrofiziologiyanın məqsədlərindən biri xarici təsirlər zamanı elektroensefaloqrafiyada (EEQ) dəyişikliklərin aşkarlanması və kəmiyyət qiymətləndirilməsidir ki, bu da kəskin serebral çatmamazlıq zamanı neyroprotektiv farmakoterapiyaya beyinin cavab reaksiyalarının formalaşması mexanizmlərini anlamaq üçün vacibdir. Təqdim edilmiş məqalənin məqsədi beyinin cavab reaksiyalarının formalaşmasının neyrofizioloji mexanizmlərini aşkar etmək üçün verilən qıcıqlar (farmakoloji təsirlər) zamanı EEQ-də vizual analiz zamanı qiymətləndirilməsi mümkün olmayan dəyişikliklərin kəmiyyət qiymətləndirilməsi olmuşdur. Material və metodlar. 2005-2011-ci illərdə Donesk regionunun klinik territorial tibb birləşməsinin neyrocərrahi mərkəzində müalicə alan 86 xəstə müayinə edilmişdir - işemik insult keçirmiş 46 pasiyent və ağır kəllə-beyin travmalı 40 pasiyent. Bütün xəstələr baş beyinin kompüter tomoqrafiyası, maqnit-rezonans tomoqrafiyası, transkranial ultrasəs doppleroqrafiya, EEQ müayinələrdən keçmişdir. Tədqiqat Tiosetam preparatının orqanizmə yeridilməsindən əvvəl və plazmada maksimal konsentrasiyası (30 dəq sonra) fonunda sutkalıq 15, 20 və $30 \mathrm{ml}$ dozada 7 gün ərzində aparılmışdır. Nəticələr. 
Farmakoloji təsir - müxtəlif nootprop preparatların yeridilməsi - fonunda reaktivliyin təsnifatı işlənib hazırlanmışdır - mərkəzi sinir sisteminin (MSS) üç tip reaksiyası (13 yarımqrup). I tip - mütləq spektral qüvvə göstəricilərinin və inteqral koeffisientlərin etibarlı dəyişikliklərinin olmamas - proqnostik qənaətbəxş sayılmır. II tip reaksiya farmakoloji təsirə cavab olaraq qabıq-qabıqaltı əlaqələrin dəyişikliklərini əks edir. III tip reaksiya beyin qabığı səviyyəsində qarşılıqlı əlaqələrin dəyişikliklərini göstərir. Tiosetamla intensiv terapiyanın effektivliyinə təsir edən amillərə funksional cavabda iştirak edən serebral strukturların, neyromediator və metabolik mexanizmlərin funksional tamlığı və Tiosetamın dozası daxildir. Yekun. Hər hans1 neyrotrop preparatın yeridilməsinə cavab olaraq MSS-nin reaksiya tiplərinin təsnifatından istifadə etməklə, preparatın istifadə edilən dozasının adekvatlığını və onun korreksiyasına ehtiyacın olmasını qiymətləndirmək mümkündür.

Açar sözlər: baş beyin insultu, kəllə-beyin travması, kəmiyyət elektroensefaloqrafiyası, spektral qüvvə, MSS-nin reaksiyalarının tipləri.

\title{
SUMMARY
}

\section{NEUROPHYSIOLOGICAL EVALUATION OF CENTRAL NERVOUS SYSTEM REACTIVITY IN RESPONSE TO PHARMACOLOGICAL EFFECT IN ACUTE CEREBRAL INSUFFICIENCY OF VARIOUS GENESIS}

\author{
${ }^{1}$ Cherniy V.I., ${ }^{2}$ Andronova I.A., ${ }^{1}$ Cherniy T.V., ${ }^{2}$ Andronova M.A. \\ ${ }^{1}$ State scientific institution "Scientific-practical center of preventive and clinical medicine" \\ of State Administration Affairs, Kyiv, Ukraine; \\ ${ }^{2}$ Donetsk national medical University of M. Gorky, Donetsk, Ukraine
}

One of the objectives of modern clinical neurophysiology is the identification and quantification of the electroencephalography (EEG) changes during the external influences. This is necessary in order to approach an understanding of the mechanisms of formation of responses of the brain during the neuroprotective pharmacotherapy for acute cerebral insufficiency (ACI). The aim of this study was the quantitative assessment of EEG changes during the stimulation (pharmacological action) that are not available by visual analysis, to identify the neurophysiological mechanisms of formation of responses of the brain. Materials and methods. The study included 86 patients, 46 patients with ischemic stroke (IS) and 40 patients with severe traumatic brain injury (STBI), who were treated in the neurosurgical centre of the Donetsk regional clinical territorial medical Association (DRCTMA) in the period of 2005-2011. We conducted computer tomography and magnetic resonance imaging of the brain, transcranial ultrasonographic doppler, EEG. The studies were conducted before the introduction and after the maximum concentration of the drug Tiocetam in plasma (in 30 minutes) in a daily dose of 15, 20 and $30 \mathrm{ml}$ for 7 days. Results. We developed the classification of the brain reactivity - three (13 subgroups) reactions of central nervous system the pharmacological effects of the introduction of various nootropic drugs. Type I is the lack of significant changes in indicators of absolute spectral power and integral coefficients is prognostically unfavorable. Reaction of type II reflect changes in cortical-subcortical interactions in response to pharmacological influence. Reaction of the III type reflected changes in interactions at the level of the cortex. Factors, which affected the efficiency of intensive therapy by Tiocetam are the functional preservation of cerebral structures, neurotransmitter and metabolic mechanisms involved in the functional response and the dose Tiocetam. Conclusion. Using the classification of types of the reactions of CNS in response to the introduction of any neurotropic drug, it is possible to assess the adequacy of the applied dose of the drug and the need for it future correction.

Keywords: cerebral stroke, traumatic brain injury, quantitative electroencephalography, spectral power, types of reaction of the CNS.

Redaksiyaya daxil olub: 02.06 .2018

Çapa tövsiya olunub: 30.06 .2018

Rayçi: professor Şiraliyeva R.K. 